\title{
Description of factors decreasing egg incubation of creole hens (Gallus gallus domesticus)
}

\author{
Rodríguez-Ortega, Leodan Tadeo ${ }^{1}$; Hernández-Guzmán, Filogonio Jesús ${ }^{1}$; Noguez-Estrada, Juan; \\ Pro-Martínez, Arturo²; González-Cerón, Fernando²; Rodríguez-Ortega, Alejandro ${ }^{1^{*}}$ \\ ${ }^{1}$ Universidad Politécnica de Francisco I. Madero, Tepatepec, Hidalgo, México. ${ }^{2}$ Colegio de \\ Postgraduados, Campus Montecillo, Montecillo, Texcoco, México. \\ *Corresponding author: arodriguez@upfim.edu.mx
}

\section{ABSTRACT}

Objective: To describe the factors that affect the incubation of fertile eggs of Creole hens (Gallus gallus domesticus) at Mezquital Valley, Hidalgo, Mexico.

Design/Methodology/Approach: 448 eggs of Creole hens were incubated in a Casser model 7622 incubator, in which the number of infertile and fertile eggs was evaluated; within the number of fertile eggs, the number of dead embryos was determined; due to dehydration or damage caused by fungi and bacteria. From the live hatched chickens, those that died due to omphalitis were recorded.

Results: 272 of 448 incubated eggs were fertile; 119 of them hatched and 153 were dead embryos. While 176 were infertile. Among the dead embryos, 84 of dehydration, 69 due to fungal and bacterial infection and 11 live hatched chicks due to omphalitis.

Limitations/implications: The literature review found little information on factors affecting the hatching of fertile Creole chicken eggs in backyard flocks.

Findings/conclusions: Infection by fungi and bacteria increase embryonic mortality, while omphalitis increases mortality during the first days of life of the backyard Creole chickens. High storage temperature in the nest or incubator causes embryo dehydration.

Keywords: embryonic mortality, bacteria, fungi, dehydration, egg infertility.

\section{INTRODUCTION}

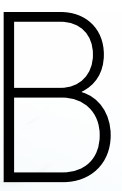

ackyard poultry farming is an important livestock activity in rural communities in Mexico. This activity strengthens the welfare of low-income families because it provides animal protein and economic income. Creole hens (Gallus gallus domesticus) are the predominant birds for backyard poultry farming; however, they face the problems of being displaced by genetically improved lines of birds, not adapted to the environments of traditional management (Rodríguez-Ortega et al., 2019). Another problem is the lack of technical management during their incubation process, which decreases hatchability and the number of live chicks. Temperature, humidity, 
ventilation, poor sanitary management of the birds and facilities, as well as bacterial and fungal infections are factors that decrease the hatchability of the fertile egg of Creole hens (Rodríguez-Moya et al., 2017). French (2009) mentioned that the optimum temperature for good embryo development is between 37 and $38{ }^{\circ} \mathrm{C}$, while the embryos immediately die when exposed to $47^{\circ} \mathrm{C}$. In contrast, embryos can withstand low temperatures for short periods, cold reduces yolk consumption by the embryo, which affects its survival (Hussain et al., 2019). Relative humidity inside the incubators significantly influences embryonic mortality and development. Van der Pol et al. (2013) reported that relative humidity between 30 and 35\% increased embryonic mortality and decreased hatching, and that, low relative humidity inside the incubator leads to increased water evaporation from the egg, causing embryonic dehydration (Noiva et al., 2014) and consequently egg weight decreased decreases the live chick's weight. Also, bacteria and fungi reduce avian hatch are in all areas of a farm; nest, floor, manure and the dust particles in the air (Bakheet et al., 2017). Both pathogens penetrate the egg through the pores of the eggshell during incubation. Salmonella spp. is one of the bacteria with the highest presence in the eggshells (Spickler et al., 2011), Escherichia coli is another pathogenic bacteria that causes embryonic death if it gets through the pores of the eggshell (Khan et al., 2016). Microscopic fungi such as Aspergillus fumigatus, Fusarium culmorum and Fusarium equiseti penetrate the egg and consequently, embryos become contaminated with spores and mycelium and die (Tomczyk et al., 2018). Based on the above, the factors that affect the incubation of the fertile egg of Creole chickens (Gallus gallus domesticus) at the Mezquital Valley, Hidalgo, Mexico.

\section{MATERIALS AND METHODS}

The research took place at the poultry facilities of the Universidad Politécnica de Francisco I. Madero (UPFIM), located in Tepatepec, Hidalgo, Mexico, at 1900 meters above sea level. The climate of the region is dry with an annual temperature ranging from $7{ }^{\circ} \mathrm{C}$ to $27^{\circ} \mathrm{C}$. A total of 448 eggs were incubated in an incubator model Casser 7622. The temperature was maintained at $37{ }^{\circ} \mathrm{C}$ and $55 \%$ relative humidity for 21 days. Before placed in the incubator, the eggs were individually cleaned with water without any disinfectant and dried with paper napkins. Relative humidity was provided by a glass container with clean water; the water was daily rechanged.
At 20 days, the eggs with embryo presence were determined by light impairment. For this, a lamp was used and the movement or shade of the embryos was observed. Infertile eggs allowed full light passage and were removed from the incubator then opened to confirm the diagnosis. The selected fertile eggs were placed in the hatcher section until day 23, during this time the number of hatched chicks was recorded. The eggs that did not hatch were opened to determine the factor that prevented their hatching. By visual inspection, it was determined if they were dehydrated or infected by fungi or bacteria. The hatched chicks were placed in a pen on a $4 \mathrm{~cm}$ thick oat straw flooring, the straw particle size was $2 \mathrm{~cm}$ commercial feed for young stage chickens and water ad libitum was provided. The temperature was constant at $30{ }^{\circ} \mathrm{C}$ during the first seven days of life, dead chicks were recorded and checked to determine the cause of death, yolk sac infection (omphalitis) was determined following the characteristics described by Khalaf et al. (2015).

The fertile egg percentage was determined as follows: [(number of fertile eggs/total eggs number) $\times 100$ ]. The embryo percentage was calculated as: [(number of eggs with embryo/number of total eggs) $\times 100$ ]. While the hatched chicks percentage was calculated as: [(number of hatched chicks/number of total eggs) $\times$ 100]. The percentage of dehydrated embryos was calculated as: [(dehydrated embryos/dead embryos) $x$ 100]. The percentage of bacterial and fungi infection was calculated as: [(number of infected embryos/number of dead embryos) $\times 100$ ]. The mortality percentage due to yolk sac infection was calculated as: [(number of dead chicks due to yolk sac infection/number of hatched chicks) $\times 100$ ]. Data were analyzed with the PROC PRINT, PROC and UNIVARIATE Procedure of SAS $\vee 9.0$ (SAS, 2011).

\section{RESULTS AND DISCUSSION}

In this research, we observed that the prolonged storage of fertile eggs in backyard production is a factor that affects their incubation, due to the uncertainty of the eggs hatching time. $61 \%$ of the eggs collected from the backyard production system were fertile, $27 \%$ of them hatched and 34\% were dead embryos. While 39\% were infertile (Table 1).

In backyard poultry farming, eggs are stored for varying lengths of time until enough are available to maximize the hatchery space. Eggs are usually stored for more than 
two weeks before their incubation. This may be a factor that decreased the number of hatched chicks (Table 1). The storage temperature is also an important factor involved in hatchability. Addo et al. (2018) observed that storage temperatures above $23{ }^{\circ} \mathrm{C}$ for more than 14 days increased embryonic mortality. In backyard systems, the fertile eggs are stored at room temperature with no care on the climate variability, this could have also been an important cause in the embryonic mortality observed in this research (Table 1 ).

Incubation is one of the most important activities in backyard poultry farming; however, multiple factors decrease fertile egg's hatchability. Bacteria and fungi are the factors that decrease embryo survival, and high embryonic mortality affects the number of backyard poultry in rural areas of Mexico. In this research, we found that the major cause of embryo death was dehydration, but bacterial and fungal infections also drastically affected embryos (Figure 1). Omphalitis was the main death cause during the first days of life of liveborn chicks (Table 2).

Excessive water loss is lethal for embryos, dehydrating and preventing them from hatching (Walsh et al., 1995). In this research, we observed that the eggshell membranes were attached to the embryo due the dehydration, which means that lack of moisture is a factor in increasing the number of dead embryos (Table 2). Temperature and humidity inside the incubator also affect the egg's water loss; however, dehydration can be generated outside the incubator during the egg's storage or in the nest, due to the late collection time, which increases its exposure to environmental variability. by the vitelline veins (Figure $1 \mathrm{C}$ ), while in the chicks that hatched and died in the first days of life, it was observed that the navel had poor scarring, their belly was swollen and dark green (Figure $1 \mathrm{D}$ ).

Ameen et al. (2017) observed that optimal conditions for fungus spores development of Aspergillus genus are adequate in the incubator. Due to the high relative humidity (55\%) and temperature $\left(37^{\circ} \mathrm{C}\right)$, the spores penetrate through the pores of the eggshell until they reach the yolk, which is an ideal substrate for their development. In this research, we report the total number of eggs with the presence of dark green mold and foul odor, thus indicating the presence of a pathogenic microorganism (Table 2 and Figure 1 A and B). Jacobsen et al. (2010) reported that Aspergillus fumigatus and Aspergillus flavus are the most frequently found pathogens in fertile hatching eggs. Infected eggs develop green mold, this description coincides with the mold that developed in the egg in Figure 1 A. Higenyi et al. (2014) observed that Pseudomonas spp., Staphylococcus aureus, Escherichia coli and Salmonella spp. are the bacteria with the highest presence inside hatching fertile eggs, which reduces hatchability and increases embryonic mortality. The presence of these bacteria is due to poor sanitary management in the backyard systems. The egg infected by bacteria in this research presented a foul odor, coinciding with Orel (1959) who reported that the eggs infected by Pseudomonas had a bad odor: putrid or sour and was, therefore, the field characteristic that confirmed the presence of a bacterial infection (Figure 1 B). AL-Ashmawy et al. (2013) reported that Pseudomona aeruginosa inside the eggs causes a putrid odor
Eggs with green mold inside were recorded (Figure 1 A) these did not have a bad odor. In contrast, eggs with black inside had a strong-bad odor (Figure 1 B). Among the embryos that did not hatch, it was observed that the yolk sac was not absorbed and was strongly vascularized
Table 2. Causes of death of embryos and live hatched chicks.

\begin{tabular}{l|r|r}
\multicolumn{3}{c}{ Cause of death in embryos } \\
\hline \multicolumn{1}{|c|}{ Variable } & $\begin{array}{c}\text { Number of } \\
\text { cases }\end{array}$ & $(\%)$ \\
\hline Dehydrated & 84 & 55 \\
\hline Bacterial and fungal infection & 69 & 45 \\
\hline Total & 153 & 100 \\
\hline Cause of death in live born chickens & & \\
\hline Omphalitis & 11 & 9 \\
\hline Healthy hatched chickens & 108 & 91 \\
\hline Total & 119 & 100 \\
\hline
\end{tabular}

The infection of the yolk sac is the main death cause during the first week of the life of chicks. Bacteria cause deterioration and decomposition of the yolk, depriving the chick of essential nutrients (Figure $1 \mathrm{C})$. The yolk is also the main source of immunity that the parent transmits to its progeny; if the yolk 
is affected, the ability to resist diseases reduces. Amare et al. (2013) observed that the main bacteria causing yolk sac infections Escherichia coli, Staphylococcus aureus and Proteus mirabilis, the infection increases the size of the yolk and reduces its absorption, their symptom is a green color with a brownish cloudy liquid and foul odor. Chicks present low body weight, a large, wet and improperly closed umbilical cord and blackened umbilicus and sometimes a foulsmelling crust (Khalaf et al., 2015). Based on the characteristics described above, the birds in Figure $1 \mathrm{C}$ and $\mathrm{D}$ showed yolk sac infection. This infection is considered an important factor that decreases chick development in the first days of life (Table 2).

\section{CONCLUSIONS}

Dehydration, fungal and bacterial infections increase embryonic mortality infertile eggs of Creole hens, while yolk sac infection increases mortality in the progeny, affecting the replacement in backyard poultry farming systems. External factors such as storage time, temperature and poor pen hygiene affect the hatchability of Creole hen eggs. Future research on backyard chicken in Mexico should focus on characterizing the fungi and bacteria present in Creole hen eggs, to design possible sanitation strategies to reduce embryonic mortality.

\section{REFERENCES}

Addo, A., Hamidu, A. J., Yaw, A. A., Adomako K. (2018) Impact of Egg Storage Duration and Temperature on Egg Quality, Fertility Hatchability and Chick Quality in Naked Neck Chickens International Journal Poultry Science 17(4): 175-183

AL-Ashmawy, M. A. M., El-Galil, K. A., Elwsaifi, S. F. (2013) The microbial burden of Pseudomonas species in different types of table eggs in Egypt. World Journal of Dairy and Food Sciences 8(2):190-195.

Amare, A., Mohammed, A. A., Shiferaw, A., Nazir, S., Negussie, H. (2013) Yolk Sac Infection (Omphalitis) in Kombolcha Poultry Farm Ethiopia. American-Eurasian Journal of Scientific Research 8 (1): 10-14.

Ameen, A. M., Mustafa, S. O., Hassan, D. R., Rajab, D. A., (2017) The Effect of Aspergillus Fungi, Other Fungus, and Isolated Salmonella and E. coli Bacteria on Poultry Farms and Poultry Hatcheries at Veterinary Laboratory in Veterinary Directorate in Duhok, Kurdistan Region of Iraq. EC Microbiology 5.2:52-58.
Bakheet, A. A., Ali, N. M., Habaty S. H. A., Nasef, S. A. (2017). Detection of Disinfectant resistant aerobic bacteria in unhatched chicken eggs. Benha Veterinary Medical Journal 2; 32 (2): 248- 259

French, N. A. (2009). The critical importance of incubation temperature Avian Biology Resch; 2 (1/2): 55-59

Higenyi, J., Kabasa, J. D. (2014). Microbial contamination load of hatching eggs in Butaleja, eastern Uganda. Animal and Veterinary Sciences; 2(2): 22-30.

Hussain, A., Bilal, M., Habib, F., Gola, B. A., Muhammad, P., Kaker, A. Yousaf, A., Khalil, R. (2019). Effects of low temperature upon hatchability and chick quality of ross-308 broiler breeder eggs during transportation. Online Journal of Animal Feed Research 9(2): 59-67.

Jacobsen, D. I., GroBe, K., Slesiona, S., Hube, B., Berndt, A., Brock, M. (2010). Embryonated eggs as an alternative infection model to investigate Aspergillus fumigatus virulence. Infection and Immunity 78(7): 2995-3006

Khalaf, J. Z., Hamed, F. W., Yassien, I. Z., Nazar, J. B. (2015). Bacteriological and pathological study of omphalitis in broiler chicks. Kufa Journal for Veterinary Medical Sciences 6(2): 17-26 
Khan, A., Rind, R., Shoaib, M., Kamboh, A. A., Mughal, G. A., Lakho, S. A., Malhi, K. K., Nizamani, A. R., Yousaf, A. (2016). Isolation, identification and antibiogram of Escherichia coli from table eggs. Journal of Animal Health and Production 4(1): 1-5.

Noiva, R. M., Menezes, A. C., Peleteiro, M. C. (2014). Influence of temperature and humidity manipulation on chicken embryonic development. BMC Veterinary Research 10(234):1-10.

Orel, V. (1959). The Spfoilage of Eggs Infected by Pseudomonas Bacteria and Different Methods of Preservation. Poultry Science 38 (6): 1302-1308

Rodríguez-Ortega, L. T., Valladares-Hernández, A. C., Vargas-Monter, J., Callejas-Hernández, J., ProMartínez, A., Vargas-Galicia, A. J., Sosa-Montes, E., González-Cerón, F., Rodríguez-Ortega, A. (2019). Evaluación del desarrollo de pollitas araucanas (Gallus inauris Castelló) y marans (Gallus gallus domesticus L.). Agroproductividad; 12 (8): 79-83.

Rodríguez-Moya, J., Cruz-Bermúdez, A. I. (2017). Factores que afectan la incubabilidad de huevo fértil en aves de corral. Nutrición Animal Tropical 11(1): 16-37.

SAS Institute Inc. (2011). SAS user's guide: statistics version. SAS Institute Inc., Cary, NC, USA. 959 pp.

Spickler, J. L., Buhr, R. J., Cox, N. A., Bourassa, D. V., Rigsby, L. L. (2011). Comparison between rinse and crush-and-rub sampling for aerobic bacteria recovery from broiler hatching eggs after sanitization. Poultry Science; 90:1609-1615.

Tomczyk, L., Stepién, L., Urbaniak, M., Szablewski, T., Cegielska-Radziejewska, R., Stuper-Szablewska, K. (2018). Characterisation of the Mycobiota on the Shell Surface of Table Eggs Acquired from Different Egg-Laying Hen Breeding Systems. Toxins 10(293):1-10.

van der Pol, C. W., van Roovert-Reijrink, I. A. M., Maatjens, C. M., van den Brand, H., Molenaar, R. (2013). Effect of relative humidity during incubation at a set eggshell temperature and brooding temperature posthatch on embryonic mortality and chick quality. Poultry Science 92:2145-2155.

Walsh, T. J., Rizk, R. E., Brake, J. (1995). Effects of temperature and carbon dioxide on albumen characteristics, weight loss, and early embryonic mortality of long stored hatching eggs. Poultry Science 74:14031410 .

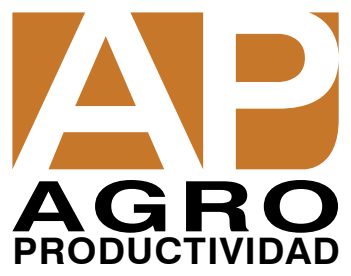

